\title{
FRBR: elucidações pertinentes
}

FRBR:

Relevant explanations

Cíntia Azevedo Lourenço ${ }^{1}$

\begin{abstract}
RESUMO
A representação descritiva e particularmente a catalogação tem sofrido nos últimos anos com uma fragilidade teórica que tem se chocado com a necessidade de atualizar as normas e padrões da representação descritiva com as atuais necessidades das bibliotecas digitais. 0 presente artigo se constitui em uma revisão de literatura sobre os últimos estudos da área realizada em pesquisa de doutorado em Ciência da Informação, onde é apresentado o FRBR: Requisitos Funcionais para Registros Bibliográficos. Esses requisitos são atualmente 0 que há de mais moderno no estudo da Representação descritiva.
\end{abstract}

Palavras-chaves: Representação descritiva. FRBR.

\section{ABSTRACT}

The descriptive representation and particularly the cataloging has suffered in the last years with a theoretical fragility that if has shocked with the necessity to bring up to date the norms and standards of the descriptive representation with the current necessities of the digital libraries. The present article if constitutes in a literature revision on the last studies of the area carried through in doctor research of in Information Science, where the FRBR is presented: Functional Requirements for Bibliographical Records. These requirements are currently what it has of more modern in the study of the descriptive representation.

Keywords: Descriptive representation. FRBR

Artigo recebido em 22/03/2019 e aceito para publicação em 29/07/2019.

1 Professora AAssociada do Departamento de Organização e Tratamento da Informação da Escola de Ciência da Informação da Universidade Federal de Minas Gerais, Brasil. E-mail: cal@eci.ufmg.br. 


\section{CENÁRIO EMI QUE NASCE 0 GRUPO DE ESTUDOS DO FRBR}

A partir do século XIX a representação descritiva de documentos começou a se constituir em foco de estudos na área da biblioteconomia. Foi nessa época que, em 1853, Charles Jewett, preocupado com a necessidade de padronização e de desenvolvimento de técnicas e normas de catalogação, propôs princípios teóricos para este processo, defendendo a criação de um catálogo universal, semente da atual catalogação cooperativa (JENG, 1997, p.119).

Também durante 0 Século XIX surgiram os primeiros códigos de catalogação em diferentes países, não existindo ainda um código reconhecido amplamente, fato que dificultava o estabelecimento de redes de catalogação e resultava em esforços isolados e repetitivos no processo de padronização da representação descritiva. Somente em 1908 surge a primeira edição do Anglo American Cataloguing Rules, AACR1, evento que veio colaborar para a efetiva padronização da representação descritiva.

Desta raiz inicial de um sistema de catalogação padronizado, surgiu mais tarde 0 formato americano Machine Readable Cataloging, MARC, visando ao intercâmbio de dados documentais (década de 1960) e as normas européias para representação descritiva, conhecidas como International Standard Bibliographic Description , ISBD, na década de 1970.

Remonta às décadas de 1980 e 19900 advento das tecnologias computacionais que desencadearam questionamentos relativos a real necessidade e à forma de se catalogar os documentos, com interferências das normas e padrões vigentes. Com o advento da internete das bibliotecas digitais, esses questionamentos se tornaram mais intensos e relevantes, ocorrendo maiores reflexões sobre o processo de catalogação que até então se fundamentava em normas e padrões, consolidados na prática biblioteconômica tradicional.

No atual contexto, são imensos os desafios no sentido de se articular os avanços técnicos da biblioteconomia tradicional com as novas possibilidades ensejadas pela tecnologia. 0 novo cenário requer dos profissionais a capacitação para atuar em novos processos, assim como o desenvolvimento de estudos mais aprofundados de novas metodologias de catalogação e indexação a serem aplicadas no tratamento da informação digital.

0 trabalho da representação descritiva hoje, nas bibliotecas digitais, a partir dos instrumentos de catalogação, criados ao longo de toda a experiência da biblioteconomia, especialmente os surgidos nos últimos dois séculos é calcado num manancial muito grande de conhecimento acumulado.

A visão do código de catalogação, como fonte de consulta para a resolução de processos de representação, ressalta o papel deste instrumento como manancial de experiência prévia acumulada, 
preservando-se tipos e características do incontável número de itens que serviu para proporcionar paulatinamente a criação das regras hoje sistematizadas. Ressalta-se, entretanto, que o conhecimento não é estático e novas necessidades sempre surgem impulsionando a atualização dos referidos instrumentos.

Como Mey (1987) pôde observar em sua pesquisa de mestrado, até o final da década de 1980, a teoria da representação descritiva e da catalogação ainda era baseada na prática do catalogador. Essa teoria possuía uma fragilidade teórica que vinha contribuindo para que os bibliotecários questionassem a validade e até mesmo a necessidade das normas de representação descritiva.

Mas com o desenvolvimento das bases de dados bibliográficas automatizadas, a necessidade de rever, estudar e reorganizar estas normas foi reconhecida em 1990, no Seminário sobre Registro Bibliográfico, realizado em Estocolmo. Este evento representa um marco para a intensificação dos estudos na área da representação descritiva, tendo contribuído significativamente para o surgimento de novas teorias.

A partir deste seminário, inúmeros estudos têm sido realizados para 0 aperfeiçoamento e evolução das normas de representação descritiva e contribuindo para o surgimento de novas iniciativas de bibliotecas digitais no ambiente web. Nesse sentido Jonson (2002, p.3), nos lembra que os princípios que sustentam o AACR2 estão sob uma intensa discussão dentro da comunidade biblioteconômica mundial.

Dois fatores que contribuíram para estas mudanças ambientais:

a) a introdução e o desenvolvimento de sistemas automatizados para bancos de dados bibliográficos;

b) 0 crescimento em larga escala de bancos de dados nacionais e internacionais com registros de várias bibliotecas que participavam de programas de catalogação cooperativa.

Surgiu, assim, uma necessidade crescente de se adaptar os códigos e as práticas de catalogaç̧ão às mudanças, às novas formas de publicação eletrônica e ao advento do acesso em rede de recursos informacionais.

\section{A REPRESENTAÇÃO DESCRITIVA DA INFORMAÇÃO E 0 FRBR}

Em pesquisa sobre as terminologias utilizadas na área de descrição documentária Lima (1998), apresenta uma definição que também faz sentido para o conceito de representação descritiva, ao afirmar que: 
[...] representar o conhecimento acumulado por um domínio é apenas uma parte do processo de tratamento documentário para que este conhecimento transformado em informação possa ser acessado pelo usuário de um Sistema de Informação e efetivar assim a comunicação documentária. (LIMA, 1998, p.56)

De acordo com Mey $(1987$, p.46) a representação descritiva tem uma função muito clara de identificação dos itens bibliográficos e uma característica, igualmente clara de adequar os catálogos ao universo de usuários.

Como marco importante dessas mudanças, o Seminar on Bibliographic Records, realizado em 1990 na cidade de Estocolmo, contribuiu para o reconhecimento no campo da biblioteconomia mundial, entre outras coisas, de que a constante pressão para se ter um "nível mínimo" de catalogação, precisava ser repensada e re-avaliada cuidadosamente. E isso teria por base não só a relação entre os elementos de dados de um registro, mas também, e principalmente, as necessidades dos usuários (IFLA, 2003).

Neste seminário, foram adotadas nove resoluções, uma das quais levou a estudos de um núcleo básico de representação descritiva, que deram origem a um grupo de estudos na IFLA para definir 0 FRBR - Exigências Funcionais para Registros Bibliográficos. Os estudos do FRBR se iniciaram em setembro de 1992 e, foram concluídos em setembro de 1997. A cronologia dos trabalhos e um esboço das atividades executadas encontram-se sintetizados no QUADRO I.

QUADRO I - Cronologia do FRBR

\begin{tabular}{|l|l|}
\hline \multicolumn{1}{|c|}{ Data } & \multicolumn{1}{c|}{ Evento } \\
\hline Set./1992 & $\begin{array}{l}\text { Os temas do estudo foram aprovados pelo Standing Committee of the IFLA Section } \\
\text { Cataloguing e são designados os membros do grupo de estudos do FRBR. }\end{array}$ \\
\hline Out./1995 & O grupo de estudos completa suas deliberações para um relatório preliminar. \\
\hline Maio/1996 & $\begin{array}{l}\text { Com as deliberações definidas, o relatório preliminar é enviado aos membros da seção de } \\
\text { catalogação da IFLA e aos comentaristas voluntários no mundo todo, para uma revisão por } \\
\text { 6 meses. }\end{array}$ \\
\hline Fev./1997 & O grupo de estudos se reúne para discutir os comentários da revisão. \\
\hline 5/Set./1997 & 0 comitê aprova o relatório final do grupo de estudos sobre o FRBR. \\
\hline
\end{tabular}

Fonte: Própria

0 grupo de estudos do FRBR teve como propósito delinear em termos claramente definidos, as funções de um registro bibliográfico em relação às várias mídias, várias aplicações e várias necessidades de usuários. Cobrir todo o alcance das funções de um registro bibliográfico em seu sentido mais amplo, isto é, um registro que não só abarque elementos descritivos, mas também pontos de acesso (autor, título, assunto etc), outros elementos de organização ( $\mathrm{n}^{\circ}$ de classificação etc) e anotações (resumos, notas de conteúdos etc). (IFLA, 1998) 
Os termos que são a base deste estudo pedem o desenvolvimento de uma arquitetura que identifique e defina claramente:

a) as entidades de interesse dos usuários de registros bibliográficos;

b) os atributos de cada entidade e;

c) os tipos de relacionamentos entre essas entidades.

0 estudo não faz suposições a priori sobre o registro bibliográfico em si, nem em termos de conteúdo ou estrutura. É uma análise focada no usuário, onde:

a) utiliza-se uma técnica de análise de entidade que começa isolando as entidades chaves que são objeto de interesse dos usuários de registros bibliográficos;

b) 0 modelo desenvolvido no estudo é inclusivo em seu âmbito mas não é exaustivo em termos de entidades, atributos e relacionamentos. Opera no nível conceitual;

c) não se limita aos usuários de bibliotecas e seus funcionários. Prevê um espectro mais amplo onde se incluem: editores, distribuidores, livrarias, serviços de recuperação de informação diversos; prevê a inclusão dos mais diversos materiais, mídias e formatos;

d) prevê a inclusão dos mais diversos materiais, mídias e formatos.

\section{A MODELAGEM DE DADOS COMO MÉTODO DE ANÁLISE DAS NORMAS E PADRÕES DA REPRESENTAÇÃO DESCRITIVA}

A metodologia utilizada neste estudo é baseada em uma técnica de análise de entidade que é utilizada no desenvolvimento de modelos conceituais para bancos de dados relacionais, que:

a) provê uma aproximação estruturada para análise das exigências de dados;

b) facilita o processo de definição e delineamento do que está sendo trabalhado neste estudo.

A análise dos elementos descritivos identificados pelo FRBR, foi desenvolvida utilizando-se da modelagem semântica de dados utilizada pela ciência da computação, através da ferramenta chamada modelo entidade-relacionamento, MER.

[...] técnicas de modelagem como a análise entidade-relacionamento e a análise orientada a objeto são comumente usadas em projetos de desenvolvimento de sistemas como um meio de compreender, em condições claramente definidas, as entidades ou objetos com os quais uma organização precisa manter informações e os relacionamentos lógicos entre essas entidades ou objetos. [...] Tais técnicas ajudam os projetistas de bancos de dados e os usuários de dados 
a entender por uma perspectiva lógica a natureza dos dados, as relações entre as entidades ou objetos e o centro de dados; e as regras que interligam estas relações. (DELSEY, 1997, p.2)

Baseados neste modelo semântico, o grupo de estudo do FRBR, identificou entidades e atributos básicos da representação descritiva, tendo sido utilizadas as seguintes fontes sobre padrões de representação descritiva: ISBD (International Standard Bibliographic Description); GARE (Guidelines fore Autorithy and reference entries); GSARE (Guidelines for Subject Autorithy and Reference Entries); UNIMAR (Marc Americano); AITF (Categories for the Description of Works of Arts).

Contudo, o FRBR não pretendeu apresentar à comunidade bibliotecária um modelo de representação descritiva definitivo. Seu objetivo maior foi apresentar sim, um nível básico para registros bibliográficos, um modelo semântico para o estudo e desenvolvimento posterior dos padrões de representação descritiva e catalogação.

A utilização de uma ferramenta de modelagem de dados utilizada em projetos de desenvolvimento de sistemas de bancos de dados pode ser justificada através da afirmação de Keen:

\begin{abstract}
Com os Sistemas Gerenciadores de Bancos de Dados, os dados ficam organizados da mesma forma que os livros de uma biblioteca. Informações como nomes e endereços ficam armazenadas num único lugar, em fita ou disco. Os softwares gerenciadores de bancos de dados possuem um recurso equivalente ao índice de autores e assuntos das bibliotecas. Os programas de processamento de transações ou geração de relatórios requisitam o registro desejado, que 0 SGBD se encarrega de localizar, da mesma forma que os leitores utilizam o catálogo de fichas da biblioteca para localizar a prateleira e o código específico do livro desejado.(...) As bibliotecas catalogam os livros por título e assunto, porém não por capítulo. A evolução dos Sistemas Gerenciadores de Bancos de Dados vêem permitindo o aprofundamento do nível de indexação - como se as bibliotecas indexassem os livros por frase ou palavra-chave. (KEEN, 1996, p. 38)
\end{abstract}

Com base neste raciocínio, as práticas de catalogação e representação descritiva, podem ser vistas como técnicas refinadas de gerenciamento de dados, que estão relacionadas não apenas à representação descritiva, mas ao detalhamento do conteúdo dos documentos digitalizados em textos completos, presentes nas bibliotecas digitais.

Propondo a aplicação de uma técnica deste tipo (...), sugerimos que se veja o processo de catalogação como nosso negócio e o próprio código como um conjunto de regras administrativas que se aplicam às entidades ou objetos que catalogamos. Desenvolvendo nosso modelo tentaríamos analisar a estrutura lógica subjacente do código, identificando em condições claramente definidas as entidades ou objetos que estão no centro desta estrutura e expressando de um modo sistemático as regras operacionais que orientam as relações entre estas entidades ou objetos (DELSEY, 1997, p.2).

A estrutura entidade-relacionamento derivada da análise de entidades, atributos e relacionamento, estão sendo usadas neste estudo como uma arquitetura para medir a relevância de cada atributo e relacionamento nas tarefas executadas por usuários de dados bibliográficos. 
Esta estrutura e o mapa de atributos e relacionamentos das tarefas do usuário, são usadas como base para as recomendações do grupo de estudos para um nível básico de funcionalidade para registros criados por exigências bibliográficas nacionais.

0 nível de importância de cada atributo ou relação para uma determinada tarefa de usuário foi baseada:

- $\quad$ no conhecimento e experiência dos membros do grupo de estudo e de consultores;

- $\quad$ em evidências coletadas na literatura de biblioteconomia e em pesquisa empírica realizada por vários peritos fora do grupo de estudo.

Uma observação importante é que o FRBR não levou em conta apenas os dados coletados entre as necessidades dos usuários de bibliotecas propriamente ditos. Os estudos foram buscar dados também entre os editores, livreiros e outros usuários de informação bibliográfica.

A metodologia utilizada nesse estudo é baseada em uma técnica de análise de entidades, para 0 desenvolvimento de modelos conceituais para bancos de dados relacionais. Esta técnica foi escolhida como base metodológica porque provê uma aproximação estruturada para análise das exigências de dados que facilita o processo de definição e delineamento do que está sendo trabalhado neste estudo (IFLA, 1998).

Contudo, é importante ressaltar que a modelagem entidade-relacionamento chegou a ser questionada pelo grupo de trabalho FRBR, que propôs que esta técnica de modelagem fosse substituída pela modelagem orientada a objeto. De acordo com Leboeuf (2001),

Michael Heaney publicou o modelo FRBR com a modelagem orientada a objeto, mas não encontrou 0 apoio que merecia, 0 que resultou em conclusões bastante semelhantes ao FRBR entidade-relacionamento. Ele a Carl Lagoze lamenta que noções como tempo, temporalidade, acontecimentos, modificações etc., não sejam contempladas no modelo FRBR com maior profundidade.

A estrutura deste modelo semântico permite o delineamento de uma arquitetura para medir a relevância de cada atributo e respectivos relacionamentos nas tarefas executadas por usuários de dados bibliográficos. Esta estrutura e o mapa de atributos e relacionamentos das tarefas do usuário, são usados como base para as recomendações do grupo de estudos, visando-se um nível básico de funcionalidade para registros criados por exigências bibliográficas nacionais.

Segundo Bergamin (2000) "de maneira explícita, o FRBR faz referência ao modelo entidaderelacionamento ao nível de projeto conceitual como ponto de partida para desenvolver uma nova 
aproximação de todo universo bibliográfico". Embora critique o caráter generalizante das entidades e alerte para o fato de que as suas relações sejam contestáveis, Boretti (1999), afirma que a escolha do modelo entidade-relacionamento "foi positiva, pois permite clareza para que situações complexas possam ser analisadas e por sua simplicidade relativa de compreensão e aplicação".

Segundo o relatório final do FRBR, os objetos chaves de interesse dos usuários de dados bibliográficos podem ser divididos em três grupos de entidade-relacionamento, como mostra 0 QUADRO 2.

Assim, nesse contexto de entidades e relacionamentos, cada entidade tem um significado específico dentro do universo da representação descritiva, e se relacionam de acordo com os objetivos e finalidades da recuperação da informação pelos usuários.

QUADRO 2 - Grupos de entidade-relacionamento, segundo o relatório final do FRBR

\begin{tabular}{|l|l|}
\hline $1^{\circ}$ GRUPO & $\begin{array}{l}\text { Inclui elementos de representação descritiva de registros bibliográficos. Estes elementos } \\
\text { se agrupam em quatro entidades básicas, relacionadas entre si: OBRA, EXPRESSÃO, } \\
\text { MANIFESTAÇÃO E ITEM. }\end{array}$ \\
\hline $2^{\circ}$ GRUPO & $\begin{array}{l}\text { Inclui as entidades que identificam a responsabilidade do conteúdo de um trabalho. São } \\
\text { as informações relacionadas aos pontos de acesso por autoria. Neste grupo identificou- } \\
\text { se duas entidades básicas: PESSOA E INCORPORAÇÃO. }\end{array}$ \\
\hline $3^{\circ}$ GRUPO & $\begin{array}{l}\text { Inclui um jogo adicional de entidades que servem como assuntos de um esforço } \\
\text { intelectual ou artístico. São entidades relacionadas também aos pontos de acesso. Neste } \\
\text { grupo foram identificadas quatro entidades: CONCEITO, OBJETO, EVENTO E LUGAR. }\end{array}$ \\
\hline
\end{tabular}

Fonte: Própria

0 primeiro grupo inclui os elementos de representação descritivos para registros bibliográficos, que são agrupados em quatro entidades básicas: OBRA, EXPRESSÃO MANIFESTAÇÃO E ITEM.

OBRA: Uma obra é uma entidade abstrata, sendo difícil definir limites precisos para esta entidade. 0 conceito de obra e a linha de demarcação entre um trabalho e outro podem ser vistos diferentemente de uma cultura para outro. Mas podemos entender esta entidade como o conteúdo da obra em si, independente de seu formato e suporte. Seria o foco da descrição atualmente, no lugar do suporte.

EXPRESSÃO: É a realização de uma obra em formatos específicos: som, imagem, objeto etc., ou numa combinação de formatos. É a forma em que uma obra é realizada de tempos em tempos. Aqui estarão representadas as tipologias documentais independente do suporte, ou seja, podemos ter um romance expresso em texto, em som, em filme etc.

MANIFESTAÇÃO: É a incorporação física da expressão de uma obra, ou seja, está intimamente focada no tipo de suporte. Quando o processo de produção envolve mudanças em sua forma física, 
o produto resultante é considerado uma nova manifestação. Assim, um romance expresso em texto, pode existir em papel, fita cassete ou em formato eletrônico de acesso local, que seriam CDs, DVDs etc.

ITEM: É um único exemplar de uma manifestação. É uma entidade concreta. Em termos de conteúdo intelectual a forma física, geralmente um item de uma manifestação é igual à própria manifestação. Mas variações podem ocorrer recorrentes de ações externas do produtor da manifestação. Essa entidade conterá informações referentes à propriedade da manifestação de uma obra, que poderá ser uma instituição ou pessoa física.

A entidade OBRA se relaciona com a entidade expressão, na medida em que uma obra é realizado através de uma EXPRESSÃO, ou seja, se uma pessoa ou instituição realiza uma obra intelectual ou artística, esta poderá ser expresso como um texto, como um som, como uma imagem etc. E uma OBRA poderá ser representado através de diversos tipos diferentes de EXPRESSÕES. Por exemplo: uma biblioteca pode ter uma mesma obra de Jorge Amado na forma de texto, som e imagem.

Já a entidade EXPRESSÃO se relaciona com a entidade MANIFESTAÇÃO, à medida que toda expressão de uma obra necessita tomar uma forma material, concreta. Assim, uma EXPRESSÃO poderá ser incorporada em várias MANIFESTAÇÕES diferentes e vice-versa. Por exemplo: as mesmas obras de Jorge Amado, necessitarão de um suporte físico para existirem, ou seja, um livro de Jorge amado (texto), uma fita cassete (som), uma fita de vídeo (imagem). A MANIFESTAÇÃO é a concretização de uma obra, é o livro, a fita de vídeo etc.

FIGURA 1: Modelo entidade-Relacionamento. Grupo 1

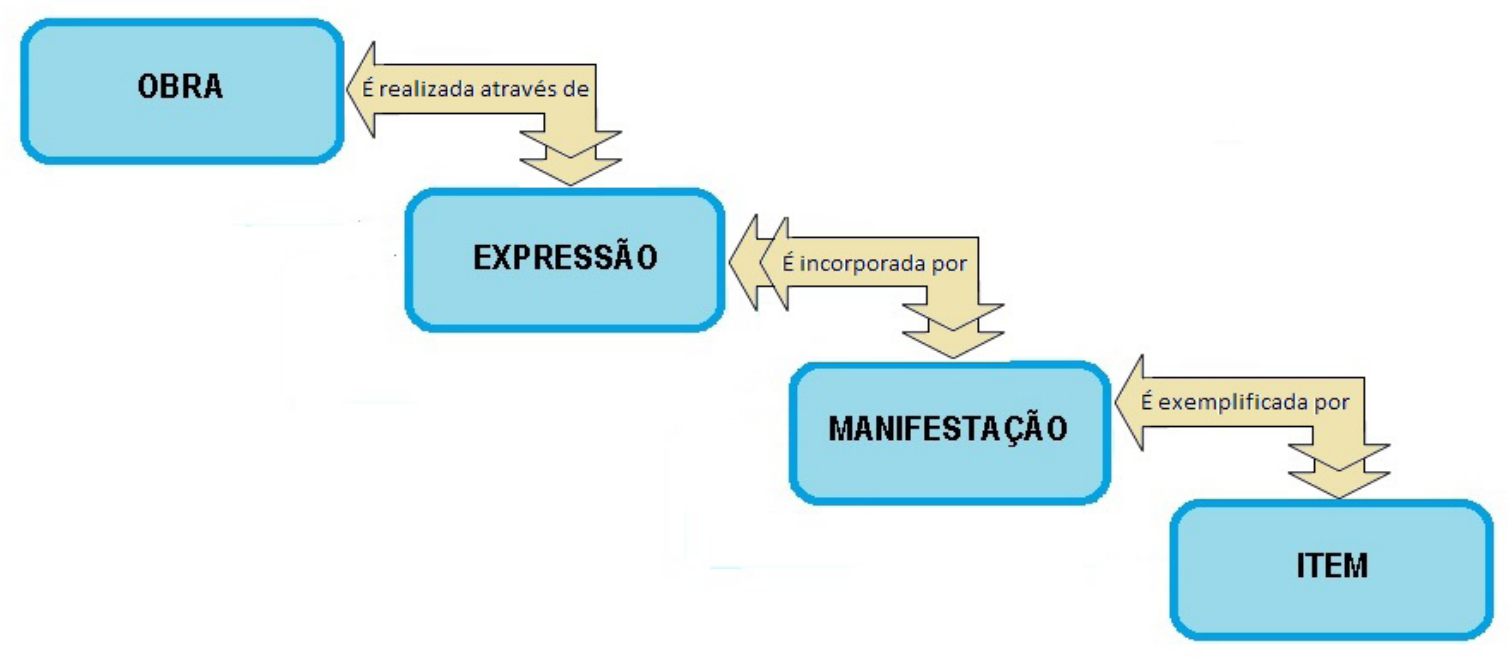

Fonte: Própria 
A entidade MANIFESTAÇÂO se relaciona com a entidade ITEM, na medida em que eu posso ter um ou mais exemplares de uma mesma manifestação. Neste sentido, uma MANIFESTAÇÃO pode ser exemplificada por um ou mais itens. Por exemplo, podemos ter em uma biblioteca vários exemplares de um livro de Jorge Amado.

$0 \operatorname{JSC}^{2}$ (2001, p.16) alerta para a relação tênue entre as entidades Expressão e Manifestação, lembrando que

Se 0 conceito de expressão será incluído nas regras, nós precisamos desenvolver diretrizes claras para os catalogadores aplicá-las. 0 ideal é que tais diretrizes sejam gerais, principalmente e tão sucintas quanto possível, de modo que este processo não seja percebido como um acréscimo de complexidade ao processo de catalogação. Diretrizes para decidir quando uma manifestação representa uma nova expressão devem ser aplicáveis a todos os formatos de materiais e devem evitar uma lista de casos especiais que necessitem de constante atualização. Nós sugerimos que elas não devem apenas descrever como diferenciar expressões, mas também devem explicar por que esta diferenciação é importante.

Definidas as entidades e os relacionamentos, são definidos os atributos das entidades, que podem ser definidos como os "campos" de um banco de dados. Os atributos são os detalhes que irão definir e identificar as partes de uma entidade.

Há atributos que são inerentes a uma entidade - meio físico, dimensões etc; e outros que são imputados externamente, que incluem:

- $\quad$ identificadores $-\mathrm{n}^{0}$ de classificação, $\mathrm{n}^{0}$ de registros etc.

- $\quad$ informação contextual - contexto político, social etc.

O segundo grupo inclui os elementos de representação de conteúdo dos registros bibliográficos, que são as informações relacionadas aos pontos de acesso por autoria, agrupados em duas entidades básicas: PESSOA e INCORPORAÇÃO.

Estas entidades não se relacionam entre si, mas constituem um grupo de entidades de pontos de acesso, que se relacionam diretamente com as entidades do grupo 1.

PESSOA: É uma pessoa, um indivíduo vivo ou falecido, envolvidos na criação ou realização de uma obra ou como assunto de uma obra.

ENTIDADE COLETIVA: É uma organização, instituição ou grupo de indivíduos responsáveis pela criação ou realização de uma obra, ou que seja o assunto de uma obra.

2 Joint Steering Committee. Format Variation Working Group 
FIGURA 2: Modelo entidade-Relacionamento. Grupo 1 e 2

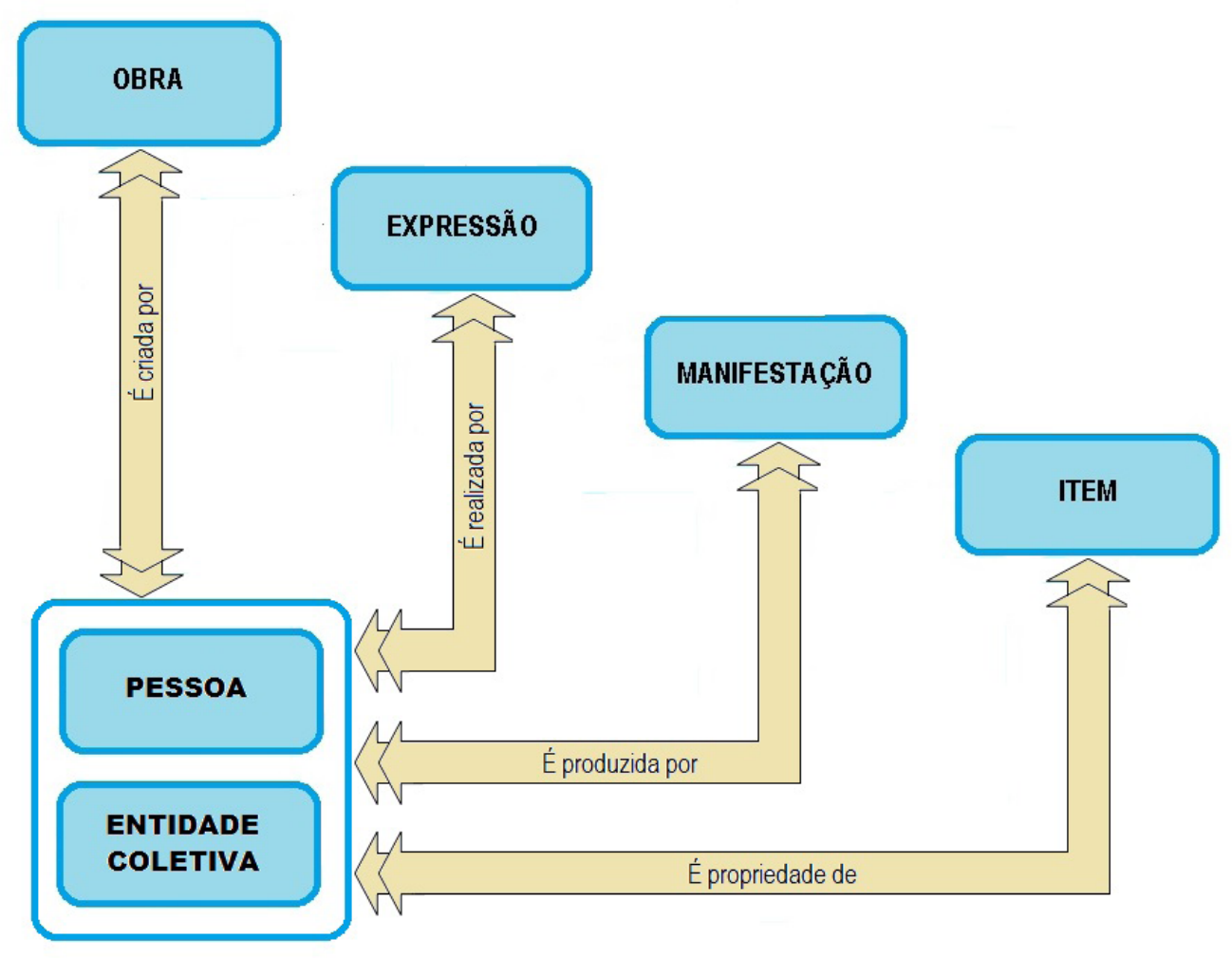

Fonte: Própria

Uma OBRA é criado por uma PESSOA ou ENTIDADE COLETIVA. Esta relação está diretamente ligada à autoria da obra em si.

Já, uma EXPRESSÃO é realizada por uma PESSOA ou ENTIDADE COLETIVA, ou seja, a incorporação de uma obra em texto requer um publicador, em som requer uma gravadora e uma imagem requer um estúdio de filmagem. Todas estas incorporações são consideradas no modelo do FRBR.

Uma MANIFESTAÇÃO, irá requerer uma PESSOA ou ENTIDADE COLETIVA que a produza. Por exemplo, um texto necessita de uma gráfica ou editora.

Neste sentido, a entidade ITEM será de propriedade de uma PESSOA ou ENTIDADE COLETIVA.

0 terceiro grupo inclui os elementos adicionais de representação de conteúdo dos registros bibliográficos, que são as informações relacionadas aos pontos de acesso por assunto ou palavrachave, agrupados em quatro entidades básicas: CONCEITO, OBJETO, EVENTO e LUGAR.

CONCEITO: É uma noção abstrata ou idéia. Envolve um alcance inclusivo de abstrações que podem ser 0 assunto de uma obra: campos de conhecimento, disciplinas, teorias etc. 
OBJETO: É uma coisa material. Envolve um alcance inclusivo de coisas que podem ser 0 assunto de uma obra: objetos animados e inanimados, objetos fixos e móveis etc.

EVENTO: É uma ação ou ocorrência. Envolve ações e ocorrências que podem ser 0 assunto de uma obra: eventos históricos, períodos etc.

LUGAR: É uma localização. Envolve localizações em geral: terrestre, histórica, características geográficas etc.

FIGURA 3: Modelo entidade-Relacionamento. Grupo 1, 2 e 3

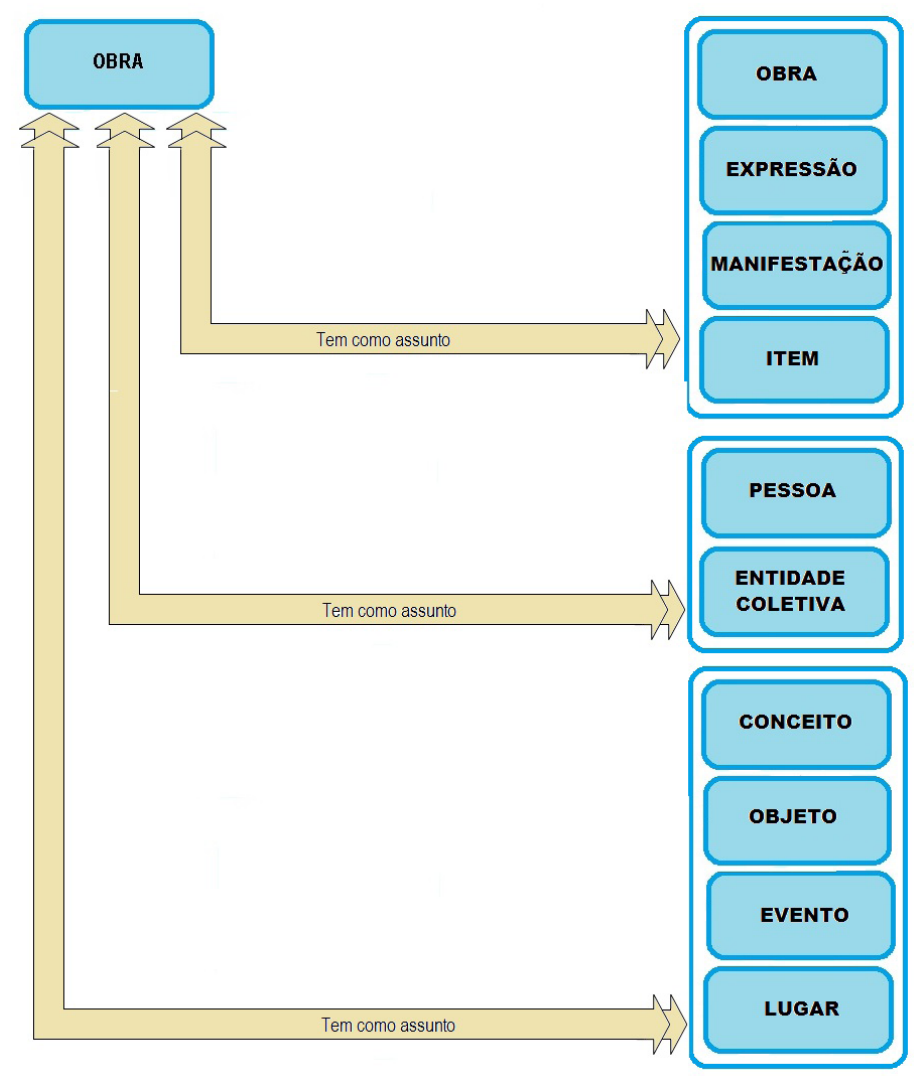

Fonte: Própria

Cada entidade definida possui um jogo de características ou atributos. Os atributos servem como meios dos usuários formularem questões e interpretar respostas de buscas.

Há atributos:

a) que são inerentes à uma entidade - meio físico, dimensões etc;

b) que são imputados externamente, que incluem:

- identificadores $-\mathrm{n}^{0}$ de classificação, $\mathrm{n}^{0}$ de registros etc.

- informação contextual - contexto político, social etc, 
Em representação descritiva, os atributos são os campos e/ou subcampos (MARC), ou áreas de descrição (ISBD, AACR) que identificam os elementos que identificam cada uma dessas entidades.

\section{QUAL A IMPORTÂNCIA DOS RESULTADOS OBTIDOS NOS ESTUDOS DO GRUPO FRBR PARA A ATUALIZAÇÃO DAS NORMAS DE CATALOGAÇÃO?}

São 2 os objetivos principais do FRBR:

a) prover uma definição clara de uma arquitetura estruturada para relacionar os dados contidos em registros bibliográficos necessários aos usuários destes registros;

b) recomendar um nível básico de funcionalidade para a criação de registros por agências bibliográficas nacionais.

No contexto da ciência da informação, teoria e prática, mudanças estão sendo urgentemente requeridas, a partir de estudos enfocando as regras clássicas que se revertem em fontes importantes para os avanços.

Leboeuf (2001), afirma que "em 1997 foi estabelecido um marco conceitual muito preciso que pode servir de base para uma reflexão sobre a natureza, propósitos e processos da descrição bibliográfica: o modelo FRBR entidade-relacionamento da IFLA.”

De acordo com o relatório final do FRBR, o uso do modelo entidade-relacionamento, MER para o estudo e aperfeiçoamento dos padrões de representação descritiva teve dois objetivos principais:

a) definir uma arquitetura estruturada que permita relacionar os dados contidos em registros bibliográficos com as necessidades dos usuários destes registros;

b) recomendar um nível básico de funcionalidade para registros bibliográficos.

No âmbito dos estudos do FRBR, um registro bibliográfico é definido como

[...] um agregado de dados que são associados com entidades descritas em catálogos de bibliotecas e bibliografias nacionais. Incluem elementos de dados descritivos; elementos de dados usados como pontos de acesso; outros elementos de dados para organização do registro em um arquivo; anotações; e dados específicos para cópias e reproduções. (IFLA, 1998)

Um registro bibliográfico é definido como um agregado de dados que são associados com entidades descritas em catálogos de bibliotecas e bibliografias nacionais e incluem elementos:

a) de dados descritivos; 
b) pontos de acesso;

c) outros elementos de dados para organização de um arquivo de registros;

d) anotações;

e) dados específicos para cópias em coleções de bibliotecas.

Neste estudo, as exigências funcionais para registros bibliográficos são definidas em relação às seguintes tarefas genéricas que são executadas por usuários quando pesquisam em bibliografias nacionais e catálogos de bibliotecas:

a) uso dos dados para encontrar materiais que correspondam ao critério de busca estabelecido pelo usuário;

b) uso dos dados recuperados para identificar uma entidade;

c) uso dos dados para selecionar uma entidade que seja apropriada às necessidades do usuário;

d) uso dos dados em de ordens de aquisição ou obtenção de acesso (empréstimo, consulta etc) para a entidade descrita.

Desta maneira as entidades são coisas que têm que ter identidade na representação da informação. Portanto, o modelo FRBR visa dar um suporte concreto para as discussões sobre a atualização e adequação às novas tecnologias das regras do AACR2R.

Com os resultados do FRBR, observou-se uma necessidade de inversão do foco da descrição bibliográfica, que atualmente está no suporte da informação, tendo em vista os próprios capítulos do código de catalogação.

Desta forma, a proposta de um novo código é que a representação descritiva seja focada no conteúdo da obra, ficando o suporte como um elemento secundário na organização da informação.

\section{O NOVO CÓDIGO DE CATALOGAÇÃO}

Segundo Tillet (2007) a nova proposta chamada inicialmente de "AACR3" não pretendia ser apenas uma atualização do AACR2R, pois o modelo atual do código é muito inflexível (preso ao suporte) e possui regras enviesadas incompatíveis com as bases atuais e à aplicação do FRBR. Assim, o nome foi alterado de AACR3 para RDA, exatamente para não ser considerado uma atualização e sim um novo conceito de código de catalogação. 
0 novo código de catalogação que será o RDA - Resource Description and Access, utiliza 0 FRBR como modelo conceitual e teórico de base. A idéia é reforçar assim os objetivos da catalogação, adequando-o ao mesmo tempo ao ambiente digital. Essa modelagem de dados, realizada pelo grupo FRBR utilizando o Modelo Entidade-Relacionamento, traz uma concretude à discussão subjetiva que existia acerca de o código de catalogação ser mais ou menos detalhista na representação descritiva.

As discussões sobre o novo código têm avançado, mas muitas dúvidas e detalhes que surgem têm também atrasado seu lançamento oficial entre a comunidade bibliotecária, que atualmente está previsto para 2010 ou 2011.

As propostas do novo código têm sido aplicadas pela OCLC na base online Worldcat (http://www. worldcat.org/), onde profissionais do mundo todo podem fazer buscas e observar as diferenças mais significativas que o RDA causará na recuperação das informações bibliográficas. 0 WorldCat Identities (beta) é um projeto experimental do grupo de estudos da IFLA sobre catalogação que implementa a futura nova versão do AACR com base no FRBR. Identifica 20 milhões de nomes de autores e mais inúmeros objetos digitais. Possui também um catálogo de autoridades: uma espécie de Who's Who online.

Há também um modelo novo para autoridades: FRAD - Requerimentos Funcionais para Dados de Autoria, com a aplicação da mesma metodologia do FRBR que têm orientado o RDA. Além disso, 0 IME ICC tem desenvolvido novos princípios da catalogação de Paris.

Dessa forma, pode-se dizer que o RDA vai comportar e conter o FRBR, sendo editado por Tom Delsey, e sua criação aceita contribuições de pessoas do mundo todo. Nesse sentido espera-se que as estruturas do RDA também sejam incorporadas no MARC21. Com a finalidade de receber essas contribuições de catalogadores do mundo todo, o site oficial do RDA (www.rdaonline.org) disponibiliza todos os relatórios e textos produzidos pelo grupo que o desenvolve, além de conter uma lista de discussão, onde discussões em português também são bem-vindas.

Os profissionais interessados em contribuir e participar desse momento histórico da catalogação mundial também podem obter mais informações em outros sites mantidos pelos colaboradores do projeto do RDA, como:
a) http://www.collectionscanada.ca/jsc/rda.html;
b) http://www.librarything.com/;
c) http://www.oclc.orglreports/2005perceptions.htm. 


\section{CONSIDERAÇÕES FINAIS}

Para Jonson (2002, p.2-3), o FRBR por si só é um fator que conduz ao desenvolvimento e tem contribuído para a compreensão teórica da atividade de catalogação entre os catalogadores do mundo todo, convertendo-se, desde a sua publicação em um marco ou ponto inevitável de referência para todos os projetos de revisão da catalogação.

Para Jonson (2002, p.6), ao contrário de sua proposta explicitada no relatório de propor um modelo de representação descritiva que atendesse às necessidades documentárias dos recursos eletrônicos, o FRBR não proporciona um modelo descritivo que atenda a contento as necessidades de objetos informacionais contidos nos mais diversos ambientes digitais. No entanto, o FRBR oferece um marco conceitual que possibilita aos estudiosos da representação descritiva, uma maneira de juntar harmoniosamente as diferentes regras de catalogação, promovendo assim, o aperfeiçoamento da interoperabilidade, tão necessária em ambientes digitais.

A catalogação se prende ao nível abstrato, raramente dando a compreensão exata de uma expressão. Esse nível de representação descritiva não está incluído entre os elementos obrigatórios de nenhum dos códigos de catalogação. 0 relatório final do FRBR reconhece atualmente esta circunstância, mas seria muito mais satisfatório se este reconhecimento fizesse parte do mesmo modelo, pois como se pode observar, são muito vagos os limites entre expressão e manifestação. (JONSON, 2002, p.6)

0 FRBR traz novidades à discussão e torna visíveis categorias inerentes às tarefas de catalogação, oferecendo uma linguagem através da qual podem ser discutidos os problemas, o nível de maturidade e de compreensão, das normas de representação descritivas.

Finalizando, o que se pode afirmar com certeza é que o FRBR não é nem uma nova regra de descrição bibliográfica e muito menos o novo código de catalogação. É uma base conceitual desenvolvida em uma técnica de modelagem de dados (MER), com o objetivo de proporcionar maior clareza às discussões de uma melhor adequação do código de catalogação ao ambiente eletrônico, através do mapeamento lógico das necessidades descritivas da representação da informação.

A idéia básica é que o novo código, ao invés de focar o suporte da informação, como tem sido até hoje, passe a focar a OBRA em si. Ou seja, informações como tipo de documentos (EXPRESSÃO) e suportes de informação (MANIFESTAÇÃO), passam a ser informações secundárias adicionais à descrição, que deverá ser focada na OBRA em si, independente de como essa obra, artística, literária ou cultural esteja sendo expressa e distribuída aos usuários de informação. 
Os elementos de descrição continuarão a ser os mesmos, a diferença estará basicamente na organização desses elementos para uma recuperação de informações mais eficiente.

Nesse contexto, está inserido também o modelo de negócio da OCLC que atualmente considera que uma biblioteca deve ser livre para o usuário de informação.

A OCLC acredita que os usuários pagariam por informação de qualidade às bibliotecas ao invés da informação duvidosa da internet. Nesse sentido, as bibliotecas passam a ter uma presença local e uma presença global, devendo se tornar parte desse universo eletrônico.

Catálogos online no futuro devem:

a) ser cada vez mais acessíveis na rede;

b) catalogar livros, pessoas etc.;

c) oferecer serviços e produtos online;

d) incluir contribuições informacionais de usuários.

0 modelo desenvolvido para este estudo representa, na medida do possível, uma visão "generalizada" do universo bibliográfico, que pretende ser independente de qualquer código de catalogação particular ou implementação para representação de conceitos.

A análise entidade-relacionamento, refletida no modelo, pode servir também como uma arquitetura conceitual útil para uma re-avaliação das estruturas utilizadas para armazenagem, exibição e comunicação de dados bibliográficos.

\section{REFERÊNCIAS}

BORETTI, Elena. An italian comment on functional requirements for bibliographic records: final report. Bollettino AlB, v.39, n.3, Set. 1999. Disponível em: http://www.aib.it/aib/commiss/catal/ frbreng.htm. Acesso em 15 out. 2002.

DELSEY, Tom. Modeling the logic of AACR. INTERNATIONAL CONFERENCE ON THE PRINCIPLES AND FUTURE DEVELOPMENT OF AACR, Toronto, 23-25 Oct. 1997. Proceedings... . Toronto: American Library Association: Library Association Publishing, 1998. p.1-16.

IFLA Study Group on the Functional Requirements for Bibliographic Records. Functional Requirements for Bibliographic Records: final report [printed text]. Munich: K. G, Saur. 1998. Disponível em: http://www.ifla.org/VII/sl3/frbr/frbr.pdf . Acesso em: 30 out. 2003.

JENG, Ling Hwey. Knowledge, technology, and research in cataloging. In: SHEARER, James R. ; THOMAS, Alan R. Cataloging and classification: trends, transformations, teaching, and training. Hardcover: Haworth Press, 1997. p.113-127. 
JSC Format Variation Working Group. Interim report 2001. Disponível em: http://www.nlc-bnc.ca/jsc/ docs/forvarwg3.pdf . Acesso em: 24 maio 2003.

LEBOEUF, Patrick. El impacto del modelo FRBR en las revisions futures de las ISBD: un challenge para la séccion de catalogación de la IFLA. IFLA COUNCIL AND GENERAL CONFERENCE: LIBRARIES AND LIBRARIANS MAKING A DIFFERENCE IN THE KNOWLEDGE AGE, 67. Ottawa, 16-25 Aug. 200. Programme and Proceedings.... Ottawa: International Federation of Library Associations and Institutions, 2001. Disponível em: <http://www.ifla.org/IV/ifla67/pprog-e.htm> Acesso em 02 nov. 2003.

LIMA, Vânia Mara Alves. Terminologia, comunicação e representação documentária. 1998. 118p. Dissertação (Mestrado em Ciências) - Escola de Comunicações e Artes, Universidade de São Paulo, São Paulo, 1992.

MEY, Eliane Serrão Alves. Catalogação e descrição bibliográfica: contribuições a uma teoria. Brasília: Associação dos Bibliotecários do Distrito Federal, 1987. 201 p.

TILLET. Bárbara. Padrões AACR2 x AACR3 - novas propostas para a descrição de recursos de informação. CONGRESSO BRASILEIRO DE BIBLIOTECONOMIA E DOCUMENTAÇÃO E CIÊNCIA DA INFORMAÇÃO. 22. 2007. Brasília. Anais ... Brasília: FEBAB, 2007. I CD-ROM. 